\title{
A New Age for Cancer Information Seeking: Are We Better Off Now?
}

\author{
Paul R. Helft, $M D^{1,2,3,4}$ \\ 'Division of Hematology/Oncology, Department of Medicine, Indiana University School of Medicine, Indianapolis, IN, USA; ${ }^{2}$ The Charles \\ Warren Fairbanks Center for Medical Ethics, Clarian Health, Inc., Indianapolis, IN, USA; ${ }^{3}$ The Indiana University Center for Bioethics, Indiana \\ University, Indianapolis, IN, USA; ${ }^{4}$ The Indiana University Melvin and Bren Simon Cancer Center, Indiana University, Indianapolis, IN, USA.
}

\begin{abstract}
A decade after the dawn of the Internet Age, are people who seek health information better off than they used to be? The current study by Arora and colleagues examines a small slice of the massive Health Information National Trends Survey dataset and attempts to understand the experiences of those US adults who have sought cancer information at any point in their lives from any source. One third reported that the information they encountered was hard to understand, and one half questioned the quality of the information they found. Several research questions regarding how individuals successfully find information on the Internet remain to be answered.
\end{abstract}

KEY WORDS: internet; health information seeking; cancer information $\mathrm{J}$ Gen Intern Med 23(3):350-2

DOI: $10.1007 / \mathrm{s} 11606-007-0496-6$

(๑) Society of General Internal Medicine 2007

\section{INTRODUCTION}

A decade after the dawn of the Internet Age, are people who seek health information better off than they used to be? Early predictions around the turn of the millennium suggested that electronic access to information would revolutionize medical practice, creating legions of download-happy medical "consumers" armed with the latest information and prepared to tackle their own health care. Newfound access to information was predicted to be a great equalizer for patients and to pose a threat to the traditional authority of doctors. ${ }^{1-3}$ But has anything changed for the better?

The National Cancer Institute (NCI) recognized that the radical shift in the way patients could obtain information from online sources raised new questions about health behaviors and health care, and realized that an understanding of information-seeking behaviors in this new age was necessary to its mission of decreasing the burden of cancer on the health of Americans. As a result, the NCI sponsored the cross-sectional study known as the Health Information National Trends Survey (HINTS) in 2002-2003. This study properly recognized that online information-seeking behavior was better understood in the context of health information seeking in general.

Published online January 15, 2008
The current study by Arora and colleagues examines a small slice of the massive HINTS dataset and attempts to understand the experiences of those US adults who have sought cancer information at any point in their lives from any source. ${ }^{4}$ Their findings suggest that more than 90 million adults in the US have sought cancer information, three quarters within the past year. The authors also found that, among the sources consulted first for cancer information, respondents sought information from health care providers only a minority of the time (10.7\%). The internet was used by US adults as the first source of cancer information nearly half of the time, by far the most popular source.

What adult information seekers found once they went looking for cancer information was dissatisfying in many cases: One third reported that the information they encountered was hard to understand, and one half questioned the quality of the information they found. Individuals with more years of formal education had better experiences, as did those with health insurance. Those individuals who went online for information were slightly more satisfied than those who first sought information from health care providers or other sources, as evidenced by the smaller proportion of those who consulted the internet first, who agreed that the information was hard to understand.

Several population characteristics of the sample cohort are worth noting. First, the individuals who responded to the HINTS survey were mostly not cancer patients themselves, although nearly $11 \%$ had a personal history of cancer, and many more reported a family history of cancer. Individuals with a personal history of cancer are likely to have encountered specific cancer information in the context of their own health care and treatment, and may, in general, have a different view of cancer information sources. Thus, the HINTS dataset is not, primarily, a study of information seeking by cancer patients. Second, the sampled cohort may not be educationally representative of US adults in general, as the 2006 US Census data suggests that more than $80 \%$ of US adults over the age of 20 are high school graduates, ${ }^{5}$ whereas only $32 \%$ of the HINTS survey cohort reported having graduated from high school. Fewer years of formal education was associated with lower informationseeking experience (ISEE) scores in the current study. Finally, about one half of the HINTS cohort had never sought cancer information, and their views are not the subject of the present analysis. The authors do not indicate whether respondents who had never sought cancer information 
differed in any substantial ways from those who had sought cancer information at any time in their lives.

Importantly, respondent characteristics accounted for only a small fraction of the variance found in ISEE scores, suggesting that important features of the information environment are more likely to influence information-seeking experiences than any of the individual socio-demographic characteristics examined in this study. A decade of research and scholarship on information seeking in the age of the internet has suggested that individuals who are younger, richer, and better educated are more likely to seek health information online. The present study's findings conform substantially to these precepts. Evidence that the "digital divide" still exists may be found in the results of this study, although evidence from other sources suggests that it may be narrowing in significant ways. ${ }^{6}$ Most disturbingly, half of those who had sought cancer information from any source agreed that "almost everything causes cancer," and three-quarters agreed that there were too many cancer prevention recommendations and that it was hard to know which to follow.

Several questions regarding this study's findings immediately come to mind. Is it a positive or negative finding that so few individuals who sought cancer information did so first from sources other than their health care provider? What factors contributed to the substantially negative experiences encountered by those who sought cancer information? Has easier access to cancer information improved the health care environment for US adults? I will take each of these questions in turn.

\section{IS IT A POSITIVE OR NEGATIVE FINDING THAT SO FEW INDIVIDUALS WHO SOUGHT CANCER INFORMATION DID SO FIRST FROM SOURCES OTHER THAN THEIR HEALTH CARE PROVIDER?}

Imagine for a moment an "average" US adult who considers seeking cancer information. Perhaps, he or she gets a new pain and wonders if it could be caused by cancer or hears a friend say that she has just started a new "anti-cancer" diet and wonders if food can prevent cancer. Perhaps this individual learns that an uncle has just been diagnosed with prostate cancer and wants to learn something about the disease. One can imagine a thousand scenarios in which a person might be driven to seek information about cancer. Although a new, personal diagnosis of cancer might mean that a patient is able to see a cancer clinician within 1 to 2 weeks (thereby gaining access to information quickly), a patient who was worried about his uncle's prostate cancer and wants to learn more may not have the option of turning immediately to his or her health care provider. The internet, in such circumstances, provides instant access to such information, at least for those who have access to the internet and the skills necessary for seeking information online. Thus, having access to several more-immediately available forms of information (internet, books) allows individuals to begin to seek answers to their burning cancer questions much sooner than they would be able to discuss it with a provider. The study's finding that adults turn more frequently to the internet and other sources first before turning to health care providers is easily explained in this way and does not seem to me to be a negative result when seen in this light. However, if people come away from their searches "frustrated and confused," then they may not be any better off.

\section{WHAT FACTORS CONTRIBUTED TO THE SUBSTANTIALLY NEGATIVE EXPERIENCES ENCOUNTERED BY THOSE WHO SOUGHT CANCER INFORMATION?}

The authors of the present study found that individual respondent characteristics had very little relative influence on cancer information seeking experiences. This finding suggests that elements of the information-seeking environment-or perhaps, other unmeasured factors-are more likely to be responsible for the negative experiences. We know that individuals who seek information online (the most popular single first information source for individuals in this cohort) do so often by entering general search terms into a search engine such as Google ${ }^{\mathrm{TM}}{ }^{7}$ What they encounter next is a large number of links, most of which lead to information that is substantially commercial in nature. ${ }^{8}$ Much of it is of questionable quality. ${ }^{9}$ Some individuals may be able to sort out the good from the bad, but exactly how best to do this is an unanswered research question. We know also that about half of the US adult population has either rudimentary or limited reading skills ${ }^{10}$ and that online materials are frequently written at about the 12 th or 13th grade level, above the reading abilities of the majority of the US population. ${ }^{11-13}$ Finally, and perhaps most important, although for a decade, researchers have identified the quality of internet information as being the most important problem associated with open and easy access to online health information, my own experience has been that patients are more commonly frustrated by their ability to find individualized information. They frequently recognize when the information they encounter is of questionable quality, and they certainly know when someone is trying to sell them something. But they have great trouble sorting out what applies to them and what does not. This problem has been characterized analogically as "drinking from the fire hose when all you want is a drink of water." 14 It is easy to find information about prostate-specific antigen testing; it is much harder to find online information that helps an individual (with all his unique attributes) to weigh the risks and benefits of testing in meaningful ways.

\section{HAS EASIER ACCESS TO CANCER INFORMATION IMPROVED THE HEALTH CARE ENVIRONMENT FOR US ADULTS?}

The authors of the present study found that respondents with the lowest levels of formal educational attainment had the lowest ISEE scores. These individuals were more likely to have negative cancer related beliefs, such as agreeing that "almost everything causes cancer." If we grant that it is not, in fact, the case that almost everything causes cancer, then why did so many information seekers agree that this is the case? Two possible explanations come to mind: The first is that individuals with less formal education are more likely to hold this type of inaccurate beliefs in the first place and that their information-seeking experiences did not disabuse them of the beliefs. The second is that such individuals seek and encounter information that persuades them to hold such inaccurate beliefs, perhaps, because they are unable to distinguish higher quality from lower quality information. In any case, what we learn from Arora's study is that the information-seeking 
experiences examined in the HINTS study do not appear to have improved the information-seeking environment for all groups equally.

A potentially fruitful area of research that has not received substantial attention to date is the examination of sociodemographic and educational factors that predict "successful" use of online sources for health information. Some individuals may know how to do it in ways that lead to positive outcomes for them, and others may suffer harms as a result of Web-based information seeking. Understanding the predictors of successful and unsuccessful information-seeking behaviors would undergird future efforts to create means of assisting patients to find high-quality, individualized information helpful to decision making and to efficient and effective medical care.

Acknowledgment: This paper was supported, in part, by an American Cancer Society Clinical Research Training grant $\mathrm{PBP}$ 105416

Corresponding Author: Paul R. Helft, MD; Division of Hematology/ Oncology, Department of Medicine, Indiana University School of Medicine, 535 Barnhill Drive, RT 473, Indianapolis, IN 46202, USA (e-mail: phelft@iupui.edu).

\section{REFERENCES}

1. Anderson JG. How the Internet is transforming the physician-patient relationship. MedGenMed 2001;3(4). http://www.medscape.com/view article/415047 [formerly published in Medscape TechMed 1(3), 2001]

2. Coiera E. The internet's challenge to health care provision. Brit Med J. 1996;312:3-4.
3. Gerber BS, Eiser AR. The patient-physician relationship in the Internet age: future prospects and the research agenda. J Med Internet Res. 2001;3:e15.

4. Arora NK, Hesse, BW, Rimer BK, Viswanath K, Clayman ML, Croyle RT. Frustrated and confused: the American public rates its cancer-related information seeking experiences. J Gen Intern Med (in press) DOI 10.1007/s11606-007-0406-y

5. US Census Bureau. http://www.census.gov/population/www/socdemo/ education/cps2006.html. Cited November 25, 2007.

6. US Department of Commerce. A nation online: entering the Broadband Age. http://www.ntia.doc.gov/reports/anol/NationOnlineBroadband04. htm. Cited November 25, 2007

7. Pew Internet and American Life Project. In: Susannah Fox, ed. Online Health Search 2006. http://www.pewinternet.org/pdfs/PIP_Online Health_2006.pdf. Cited November 26, 2007.

8. Sajid MS, Iftikhar M, Monteiro RS, Miles AFW, Woods WGA, Baig MK. Internet information on colorectal cancer: commercialization and lack of quality control. Colorectal Dis. DOI: 10.1111/j/1463-1318.2007.01316.x

9. Eysenbach G, Powell J, Kuss O, Sa E. Empirical studies assessing the quality of health information for consumers on the world wide web: a systematic review. JAMA. 2002;287:2691-700.

10. Weiss BD, Coyne C, Michielutte R, Davis TC. Communicating with patients who have limited literacy skills: consensus statement from the National Work Group on Literacy and Health. J Fam Pract. 1998;46: 168-76.

11. Friedman DB, Hoffman-Goetz L, Arocha JF. Readability of cancer information on the Internet. J Cancer Educ. 2004;19:117-22.

12. Friedman D, Hoffman-Goetz L, Arocha J. Health literacy and the world wide web: comparing the readability of leading incident cancers on the Internet. Med Inform Internet Med. 2006;31:67-87.

13. Kaphingst KA. Accessibility of Web sites containing colorectal cancer information to adults with limited literacy. Cancer Causes Control. 2006; 17:1573-75.

14. Bender E. Internet medical information in need of good filter. Psychiatric News 2004; 39(23): 24. http://pn.psychiatryonline.org/cgi/content/ full/39/23/24. Cited November 25, 2007. 